\title{
EPOXIDAÇÃO DE ÓLEOS DE SOJA, GIRASSOL E MAMONA E AVALIAÇÃO QUIMIOMÉTRICA POR PCA E HCA
}

\author{
Fernanda Carla Bock ${ }^{1}$ \\ Lilian F. Ferreira da Silva ${ }^{2}$ \\ Rosana de Cássia de Souza Schneider ${ }^{3}$ \\ Luciano Marder ${ }^{4}$
}

\section{RESUMO}

Este estudo teve por objetivo realizar a epoxidação de diferentes óleos vegetais (girassol, mamona e soja) e realizar a identificação, assim como o acompanhamento reacional, através da espectroscopia no infravermelho médio, aplicando métodos multivariados de análise (análise de componentes principais - PCA e análise de agrupamento hierárquico - HCA). Os resultados obtidos mostraram que é possível obter epóxidos a partir de ésteres dos óleos de mamona, soja e girassol e que a taxa de conversão está associada ao tempo, à quantidade de enzima e ao óleo vegetal empregado. É indicada a possibilidade do acompanhamento reacional através da espectroscopia no infravermelho médio associado à análise de componentes principais (PCA). Também apresenta a viabilidade de identificação dos epóxidos obtidos a partir de óleos de girassol, mamona e soja através da espectroscopia no infravermelho médio associada à análise de componentes principais (PCA) e análise por agrupamento hierárquico (HCA).

Palavras-chave: Epoxidação. Óleos vegetais. Infravermelho. Quimiometria

\begin{abstract}
This research aims to perform the epoxidation of different kinds of vegetable oils (sunflower, castor and soybean) and identify them as well as the reaction monitoring by mid-infrared spectroscopy applying multivariate analysis methods (principal component analysis - PCA and hierarchical cluster analysis - HCA). The results showed that it is possible to obtain epoxides from esters of castor oil, soybean and sunflower and that the conversion rate is associated with time, the amount of enzyme and the vegetable oil applied. The research also indicates that the reaction can be monitored by means of mid-infrared spectroscopy associated with principal component analysis (PCA) and the identification of epoxides obtained from sunflower oils, castor and soybean by mid-infrared spectroscopy combined with the analysis of the principal components analysis (PCA) and the hierarchical cluster analysis(HCA).
\end{abstract}

Keywords: Epoxidation, Vegetable oils, Infrared, Chemometrics.

\footnotetext{
${ }^{1}$ Departamento de Química e Física da Universidade de Santa Cruz do Sul - UNISC. <fernanda.c.bock@gmail.com>

${ }^{2}$ Departamento de Química e Física da Universidade de Santa Cruz do Sul - UNISC. <lilianferreira93@hotmail.com>

${ }^{3}$ Departamento de Química e Física da Universidade de Santa Cruz do Sul - UNISC. <rosana@unisc.br>

${ }^{4}$ Departamento de Química e Física da Universidade de Santa Cruz do Sul - UNISC. <lucianomarder@unisc.br>
} 


\section{INTRODUÇÃO}

Novas tecnologias visando ao desenvolvimento de produtos de fontes renováveis surgem a cada década. Isto ocorre devido ao aumento das preocupações sobre o uso de produtos derivados do petróleo causado pelo esgotamento progressivo das reservas mundiais de combustíveis fósseis, mas também devido a preocupações sobre seu impacto ambiental. Os óleos vegetais constituem uma alternativa adequada para substituir óleos minerais, sendo que eles são totalmente biodegradáveis, não tóxicos, e "geralmente considerados como seguros" (CAMPANELLA et al., 2010).

Os óleos vegetais são de fácil obtenção através da prensagem das sementes de plantas oleaginosas e possuem grande produção e diversidade de culturas no Brasil. Os óleos vegetais podem sofrer inúmeras transformações químicas, tornando-se produtos ou intermediários para diversas aplicações nas indústrias como na área de alimentos, fármacos, plásticos, tintas, entre outros.

A produção mundial de óleos vegetais aumentou aproximadamente $400 \%$ entre 1974/75 e 2006/07, passando de 25,7 milhões de toneladas para 123,1 milhões de toneladas. Somente entre 2004/05 e 2006/07, de acordo com projeções do United States Department of Agriculture (USDA), o consumo se elevou em 27 milhões de toneladas. No Brasil, o consumo anual de óleos vegetais está em torno de 3,72 milhões de toneladas (NUNES, 2007).

A epoxidação de óleos vegetais confere maior reatividade aos óleos, tornando-os intermediários importantes com inúmeras aplicações industriais. A reação de epoxidação via perácido orgânico vem sendo estudada há muito tempo e promove a adição de um oxigênio nas insaturações $(\mathrm{C}=\mathrm{C})$ de determinados substratos. Por outro lado, o uso de epoxidação quimio-enzimática em sistema bifásico é promissor, uma vez que diminui a agressividade química do meio e leva à maior seletividade de reação (RÜSCH et al., 1999; SCHNEIDER et al., 2009).

Para a análise de óleos vegetais são empregadas, usualmente, as técnicas de cromatografia de alta eficiência (CLAE), cromatografia gasosa (CG), cromatografia por exclusão de tamanho (CE) e cromatografia em camada delgada (CCD) (KNOTHE, 2006). Porém, essas análises necessitam de um tempo significativo, consomem solvente e destroem as amostras analisadas. A espectroscopia no infravermelho é uma técnica que está sendo cada vez mais empregada, principalmente por ser rápida e não gerar grandes proporções de resíduos (FERRÃO et al., 2011; WERLANG et al.,2013). 
A espectroscopia no infravermelho associada às técnicas de análise por componentes principais (PCA) e análise por agrupamento hierárquico (HCA) já foi empregada para a identificação e discriminação de óleos e ésteres vegetais em outros trabalhos como de Trindade et al. (2005), Schneider et al. (2009) e Mueller et al. (2013).

No trabalho realizado por Muller et al. (2013) foi utilizada a espectroscopia no infravermelho, associada à análise multivariada, para identificar óleos vegetais utilizados como matéria-prima para a produção de biodiesel. Os óleos utilizados foram de canola, algodão, milho, palma, girassol e soja. Através dos resultados foi possível observar que se pode diferenciar os óleos vegetais através da espectroscopia de infravermelho associada às técnicas de PCA, HCA, análise de componentes principais por intervalos (IPCA) e o método de classificação SIMCA.

Já Trindade e colaboradores (2005) analisaram óleos vegetais empregando os espectros de reflexão total atenuada horizontal (HATR), associada às técnicas de PCA e HCA para identificar e discriminar os óleos de algodão, arroz, canola, girassol, mamona, milho e soja. Com os resultados obtidos, concluíram que a espectroscopia associada à análise multivariada é uma excelente ferramenta para diferenciação de amostras de óleos vegetais comercializados no Brasil.

Schneider e colaboradores (2009) utilizaram a espectroscopia no infravermelho, associada às técnicas de PCA e HCA, para identificar as melhores condições para realizar a produção de biodiesel a partir de óleo de fritura.

Este trabalho teve como objetivos a transformação de óleos vegetais em epóxidos por método quimio-enzimático, acompanhamento por quimiometria da epoxidação de ésteres metílicos. Buscou-se avaliar o grau de conversão e as condições de reação, e a identificação de epóxidos de diferentes origens através da espectroscopia no infravermelho aplicando métodos quimiométricos (PCA e HCA).

\section{MATERIAIS E MÉTODOS}

\subsection{Reação de esterificação do óleo vegetal}

A reação de transesterificação foi realizada em um balão de $500 \mathrm{~mL}$ onde foram adicionados $100 \mathrm{~g}$ de óleo vegetal e $100 \mathrm{~mL}$ de solução metanólica de $\mathrm{NaOH}$ a $2 \%$ previamente preparada, conforme Schneider e colaboradores. A mistura foi aquecida até $70^{\circ} \mathrm{C}$ 
em banho de óleo e permaneceu por $20 \mathrm{~min}$. sob forte agitação e refluxo até a completa solubilização dos óleos. Após, adicionou-se lentamente $22 \mathrm{~mL}$ de $\mathrm{BF}_{3} / \mathrm{CH}_{3} \mathrm{OH}(40 \%)$ ao meio reacional e deixou-se em refluxo por mais $10 \mathrm{~min}$. Para a separação dos ésteres obtidos foram acrescentados $100 \mathrm{~mL}$ de heptano e mantido o refluxo por mais $10 \mathrm{~min}$.(SCHNEIDER et al., 2004).

Após a mistura reacional foi resfriada a temperatura ambiente e acrescida de $50 \mathrm{~mL}$ de solução saturada de cloreto de sódio para melhorar a separação da fase heptânica. A fase aquosa foi descartada e a fase orgânica foi seca com $\mathrm{Na}_{2} \mathrm{SO}_{4}$ anidro (previamente seco em estufa a $120^{\circ} \mathrm{C}$ ), filtrada e o solvente evaporado em evaporador rotatório a $80^{\circ} \mathrm{C}$.

\subsection{Reação de epoxidação}

A reação de epoxidação quimioenzimática foi realizada adicionando em erlenmeyer com tampo: éster do óleo vegetal $(1 \mathrm{~g})$, diclorometano $(6 \mathrm{~mL})$, água deionizada $(5 \mathrm{~mL})$, peróxido de hidrogênio 30\% (1mL) e lipase Novozyme M435 ${ }^{\circledR}(100$ a $150 \mathrm{mg}$ ). Foram adicionados no meio reacional nesta ordem, em shaker orbital à $30^{\circ} \mathrm{C}, 275 \mathrm{rpm}$, por período de reação 12 a 36 h (SCHNEIDER et al., 2009). Foi realizado um total de nove condições experimentais variando a quantidade de enzima e tempo de separação da fase orgânica da fase aquosa E, por fim, foi realizada a remoção do diclorometano da fase orgânica por rotaevaporação à pressão reduzida.

\subsection{Análises instrumentais}

\subsubsection{Cromatografia Gasosa com detector de massas acoplado (CG-MS)}

Para análise cromatográfica, a amostra foi diluída em diclorometano na proporção de $20 \mathrm{mg} \mathrm{mL}^{-1}$. A amostra foi analisada em cromatógrafo a gás com espectrômetro de massas modelo GCMS-QP2010 Plus (Shimadzu), associado com auto injetor AOC-20i. A coluna

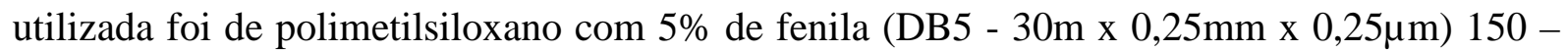
$260^{\circ} \mathrm{C}$. A injeção foi no modo Split (1:10), temperatura $250^{\circ} \mathrm{C}$, fluxo de $1 \mathrm{~mL} \mathrm{~min}^{-1}$ de Hélio. No detector de massas foi utilizada a temperatura de $280^{\circ} \mathrm{C}$ e a temperatura interface foi $280^{\circ} \mathrm{C}$. 


\subsubsection{Espectroscopia no infravermelho (FT-IR)}

Para a análise por espectroscopia no infravermelho, foi utilizado espectrômetro modelo Spectrum 400 FT-IR/FT-NIR da PerkinElmer, acoplado do acessório UATR. As amostras foram analisadas nas faixas de $4.000 \mathrm{~cm}^{-1}$ a $650 \mathrm{~cm}^{-1}$, com 32 varreduras numa resolução de $4 \mathrm{~cm}^{-1}$. Os espectros obtidos foram tratados utilizando o software Nicolet's OMNIC E.S.P para melhor interpretação dos resultados.

\subsection{Quimiometria}

Para os espectros dos ésteres e produtos das reações de epoxidação, obtidos por espectroscopia no infravermelho, foi realizada análise quimiométrica de dados empregando o aplicativo Pirouette ${ }^{\circledR}$ da Infometrix. Para a análise por componentes principais (PCA), as informações espectrais foram processadas utilizando toda região espectral (girassol e soja) e a região espectral de 1060 a $1004 \mathrm{~cm}^{-1}$ (mamona). Os dados obtidos foram centrados na média como forma de pré-processamento e também foi empregada a técnica variação normal padrão (SNV) e a primeira derivada para a análise da matriz de dados.

Para os produtos das reações de epoxidação com percentual de conversão acima de $90 \%$, foi realizada a PCA e análise por agrupamento hierárquico (HCA), utilizando as regiões espectrais 692 a $1842 \mathrm{~cm}^{-1}$ e 2481 a $3652 \mathrm{~cm}^{-1}$. Os gráficos dos scores da PCA e os dendogramas da HCA foram construídos com os dados autoescalados e primeira derivada.

\section{RESULTADOS}

\section{1 Óleo de girassol}

As amostras de óleo, éster e epóxido de girassol foram submetidas à análise de infravermelho para verificar as transformações químicas. Na Figura 1 podem ser observados os espectros no infravermelho do óleo, éster e éster metílico de girassol epoxidado. 
Figura 1 - Espectro no infravermelho do óleo (A), éster (B) e éster metílico epoxidado de girassol $(\mathbf{C})$.
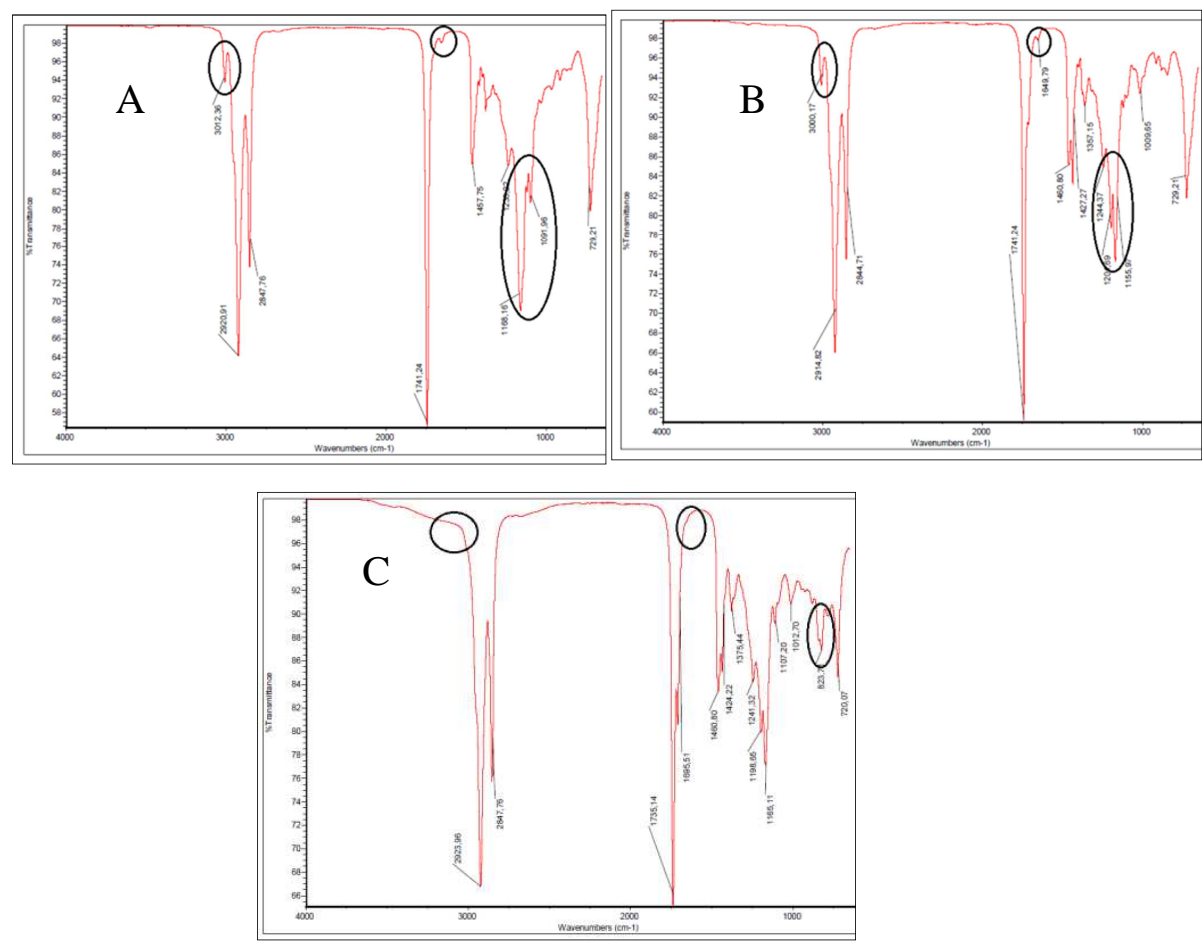

Observa-se que o espectro obtido para o óleo de girassol é muito semelhante ao espectro do éster. Isto ocorre porque a mudança estrutural é muito pequena entre as duas moléculas. A transesterificação pode ser evidenciada pelas três bandas das vibrações de deformação axial C-O nas regiões de $1.244 \mathrm{~cm}^{-1}, 1.201 \mathrm{~cm}^{-1}$ e $1.155 \mathrm{~cm}^{-1}$, característicos de ésteres metílicos de ácidos graxos de cadeia longa, sendo que a última apresenta uma maior intensidade que as demais. Verificou-se, também, a presença das bandas na região de $3.000 \mathrm{~cm}^{-1}$ (deformação axial de $\mathrm{C}-\mathrm{H}$ ) e $1.649 \mathrm{~cm}^{-1}$ (deformação axial de $\mathrm{C}=\mathrm{C}$ ), que caracterizam a presença de insaturação na estrutura da molécula. Como o óleo e os ésteres metílicos mantêm a mesma estrutura dos ácidos graxos iniciais, as bandas que indicam que houve reação estão relacionadas às ligações C-O do éster (SILVERSTEIN et al., 1994).

Após a reação de epoxidação, as bandas características de insaturação $\left(3.000 \mathrm{~cm}^{-1}\right.$, deformação axial de $\mathrm{C}-\mathrm{H}$, e $1.649 \mathrm{~cm}^{-1}$, deformação axial de $\mathrm{C}=\mathrm{C}$ ) não foram apresentadas no espectro do epóxido, o que confirma o consumo da insaturação da molécula e a eficiência da reação. $\mathrm{O}$ anel oxirano, presente na molécula epoxidada, pode ser evidenciado pela banda em $823 \mathrm{~cm}^{-1}$, associada à absorção em $820 \mathrm{~cm}^{-1}$ já existente no espectro do óleo. Esta banda corresponde às vibrações de deformações axial assimétrica do anel oxirano onde a ligação CC contrai enquanto ambas as ligações C-O estiram (SILVERSTEIN et al., 1994). 
$\mathrm{Na}$ Tabela 1 são apresentados os rendimentos das reações de transformação do éster em epóxido. O rendimento foi calculado através da medida das áreas obtidas no cromatograma após análise por cromatografia gasosa.

Tabela 1 - Resultados de epoxidação do éster metílico do óleo de girassol.

\begin{tabular}{c|ccc}
\hline Amostra & Enzima $(\mathbf{g})$ & Tempo $(\mathbf{h})$ & Rendimento (\%) \\
\hline $\mathbf{1}$ & 100 & 12 & 61 \\
$\mathbf{2}$ & 150 & 12 & 67 \\
$\mathbf{3}$ & 125 & 12 & 61 \\
$\mathbf{4}$ & 100 & 24 & 81 \\
$\mathbf{5}$ & 150 & 24 & 85 \\
$\mathbf{6}$ & 125 & 24 & 78 \\
$\mathbf{7}$ & 100 & 36 & 89 \\
$\mathbf{8}$ & 150 & 36 & 97 \\
$\mathbf{9}$ & 125 & 36 & 97 \\
\hline
\end{tabular}

Condições: $1 \mathrm{~g}$ de amostra; temperatura de $30^{\circ} \mathrm{C}$; agitação de $275 \mathrm{rpm}$.

Observou-se que o rendimento da reação é proporcional à quantidade de enzima e o tempo de reação. Conforme o aumento desses fatores, maior foi a conversão. Os resultados desta análise foram comparados com os resultados obtidos por espectroscopia, visando a obter uma resposta mais rápida no monitoramento da reação.

A Figura 2 apresenta o conjunto de espectros do éster e dos produtos de reação do óleo de girassol com identificação numérica das amostras conforme Tabela 1. Para a melhor visualização da separação das amostras, os dados foram centrados na média e foi empregada a técnica de variação normal padrão.

\section{Figura 2 - Gráfico dos scores de PC1 versus PC3}

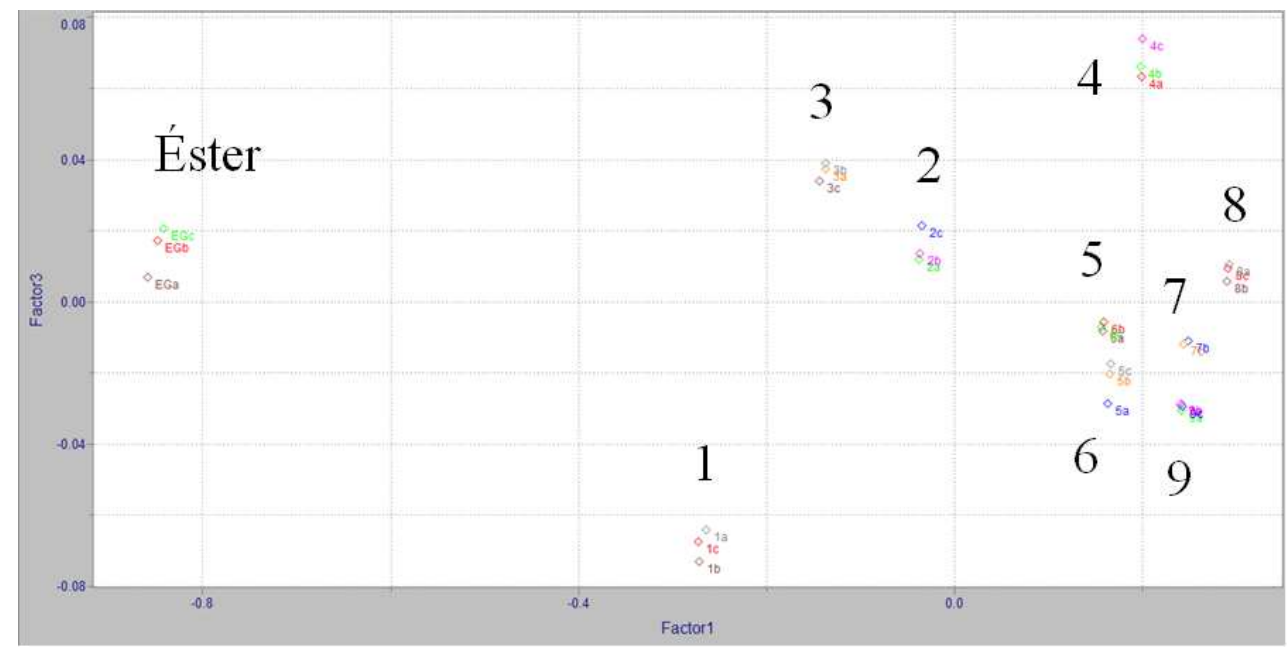


A análise de componentes principais mostrou que 98,6\% da informação contida nos dados obtidos por espectroscopia pode ser representada em três componentes principais. $\mathrm{Na}$ Figura 2 é apresentado o gráfico dos scores de PC1 versus PC3. A PC1 discrimina os produtos de epoxidação com relação ao material de partida (éster metílico de óleo de girassol), bem como os produtos de epoxidação que correspondem a conversões parciais e conversões quase completas.

\section{2 Óleo de mamona}

As amostras de óleo, éster metílico e éster metílico epoxidado de mamona foram submetidas à análise de infravermelho para verificar as transformações químicas. Na Figura 3 podem ser observados os espectros de infravermelho do óleo, éster epóxido de mamona.

Figura 3 - Espectro de infravermelho do óleo (A), éster metílico (B) e do éster metílico de mamona $(\mathbf{C})$.
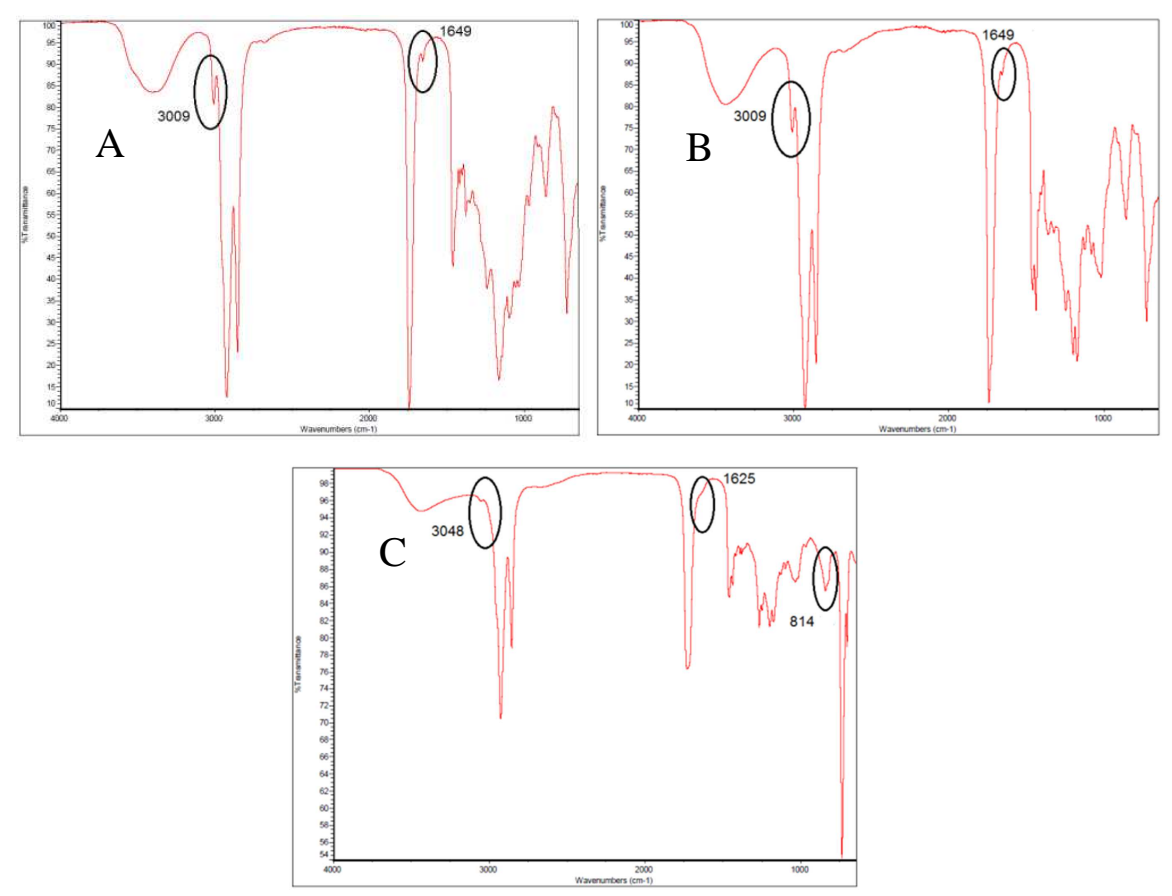

O espectro obtido para o éster é muito semelhante ao espectro do óleo de mamona, pelo mesmo motivo descrito para o óleo de girassol, ou seja, a transformação é apenas nas ligações C-O. Nos espectros são visíveis as bandas relativas às insaturações em $3.009 \mathrm{~cm}^{-1}$ (deformação axial de $\mathrm{C}-\mathrm{H}$ ), $1.649 \mathrm{~cm}^{-1}$ (deformação axial de $\mathrm{C}=\mathrm{C}$ ) e da presença de $\mathrm{O}-\mathrm{H}$ devido à banda característica na região de 3.100 e $3.500 \mathrm{~cm}^{-1}$ (SILVERSTEIN et al., 1994). 
Após a reação de epoxidação, as bandas características de insaturação $\left(3.009 \mathrm{~cm}^{-1}\right.$, deformação axial de $\mathrm{C}-\mathrm{H}$, e $1.649 \mathrm{~cm}^{-1}$, deformação axial de $\mathrm{C}=\mathrm{C}$ ), presentes no espectro do éster, não aparecem no espectro do epóxido, o que confirma o consumo da insaturação da molécula e a eficiência da reação. $O$ anel oxirano presente no produto de epoxidação enzimática pode ser evidenciado pela banda em $814 \mathrm{~cm}^{-1}$, conforme discutido anteriormente (SILVERSTEIN et al., 1994).

Os rendimentos das reações de epoxidação quimioenzimática estão apresentadas na Tabela 2.

Tabela 2 - Resultados de epoxidação do éster metílico do óleo de mamona.

\begin{tabular}{c|ccc}
\hline Amostra & Enzima $(\mathbf{g})$ & Tempo(horas) & Rendimento (\%) \\
\hline $\mathbf{1}$ & 100 & 12 & 35 \\
$\mathbf{2}$ & 150 & 12 & 40 \\
$\mathbf{3}$ & 125 & 12 & 44 \\
$\mathbf{4}$ & 100 & 24 & 66 \\
$\mathbf{5}$ & 150 & 24 & 59 \\
$\mathbf{6}$ & 125 & 24 & 42 \\
$\mathbf{7}$ & 100 & 36 & 54 \\
$\mathbf{8}$ & 150 & 36 & 72 \\
$\mathbf{9}$ & 125 & 36 & 44 \\
\hline
\end{tabular}

O rendimento foi inferior ao obtido para o óleo de girassol. No entanto, a conversão parcial pode ser importante para a aplicabilidade deste produto. Uma avaliação quimiométrica semelhante ao girassol foi realizada para o conjunto de espectros da mamona e observou-se um comportamento semelhante na apresentação das amostras, no qual a componente principal 1 é a responsável pela separação das amostras quanto ao grau de conversão.

\section{2 Óleo de soja}

Da mesma forma que ocorreu para os óleos de girassol e mamona, o óleo de soja sofreu transesterificação e epoxidação quimioenzimática. Os espectros representativos do óleo, éster metílico e éster metílico epoxidado estão na Figura 4. 
Figura 4 - Espectro de infravermelho do óleo (A), éster metílico (B) e éster metílico epoxidado de soja $(\mathrm{C})$.
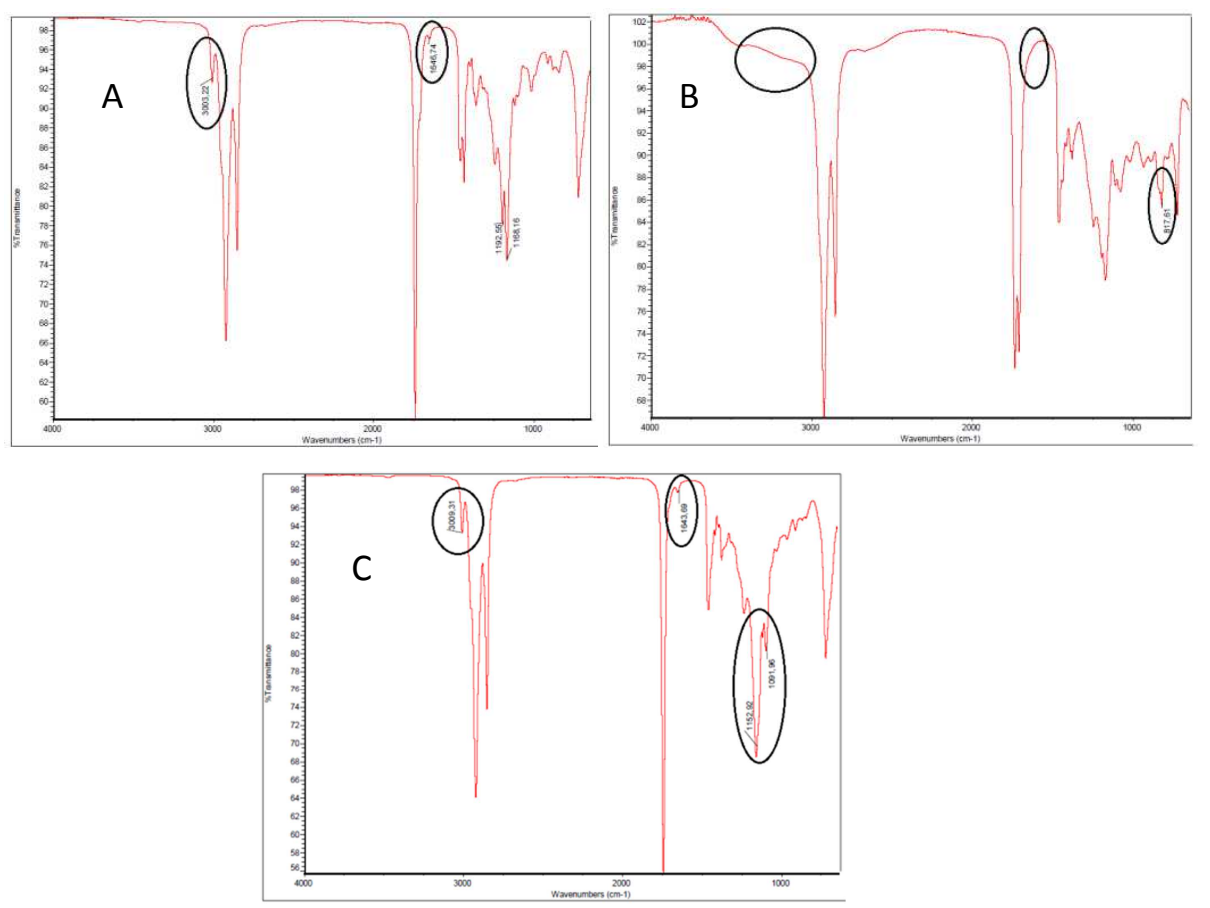

A conversão total observada nos espectros também é evidenciada na Tabela 3.

Tabela 3 - Resultados de epoxidação do éster metílico do óleo de soja.

\begin{tabular}{c|ccc}
\hline Amostra & Enzima (g) & Tempo (horas) & Rendimento (\%) \\
\hline $\mathbf{1}$ & 100 & 12 & 70 \\
$\mathbf{2}$ & 150 & 12 & 86 \\
$\mathbf{3}$ & 125 & 12 & 87 \\
$\mathbf{4}$ & 100 & 24 & 99 \\
$\mathbf{5}$ & 150 & 24 & 99 \\
$\mathbf{6}$ & 125 & 24 & 99 \\
$\mathbf{7}$ & 100 & 36 & 99 \\
$\mathbf{8}$ & 150 & 36 & 99 \\
$\mathbf{9}$ & 125 & 36 & 99 \\
\hline
\end{tabular}

Condições: $1 \mathrm{~g}$ de amostra; temperatura de $30^{\circ} \mathrm{C}$; agitação de $275 \mathrm{rpm}$.

Também foi realizada uma avaliação quimiométrica para as amostras de soja, onde o resultado foi semelhante ao dos óleos de girassol e mamona, sendo que o Componente Principal 1 foi a responsável pela separação dos epóxidos e do éster, assim com também discrimina as amostras quanto ao seu grau de conversão.

Para os produtos das reações de epoxidação com percentual de conversão acima de 90\% foi realizada análise por componentes principais (PCA) e análise por agrupamento hierárquico (HCA), a partir dos espectros obtidos por espectroscopia no infravermelho. Nas Figuras 4 e 5 podem ser observados os resultados obtidos para PCA e HCA. 
Figura 4 - Gráfico de scores dos óleos de girassol, soja e mamona

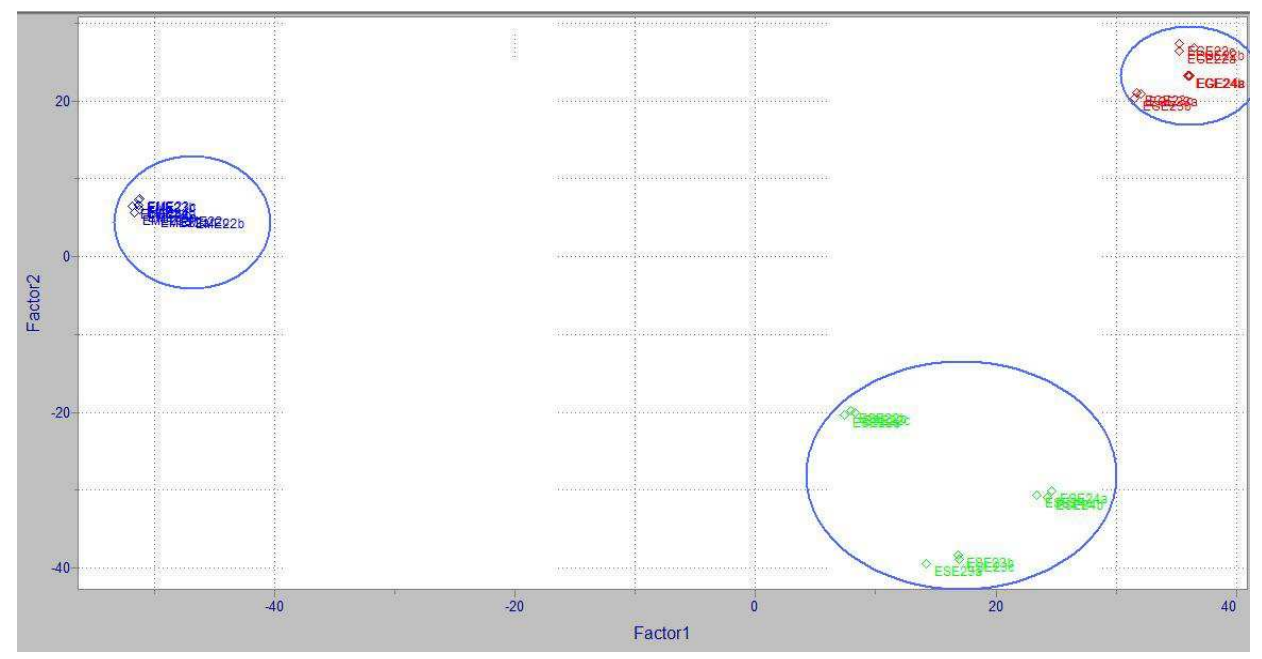

Figura 5 - Dendograma das amostras de girassol, soja e mamona

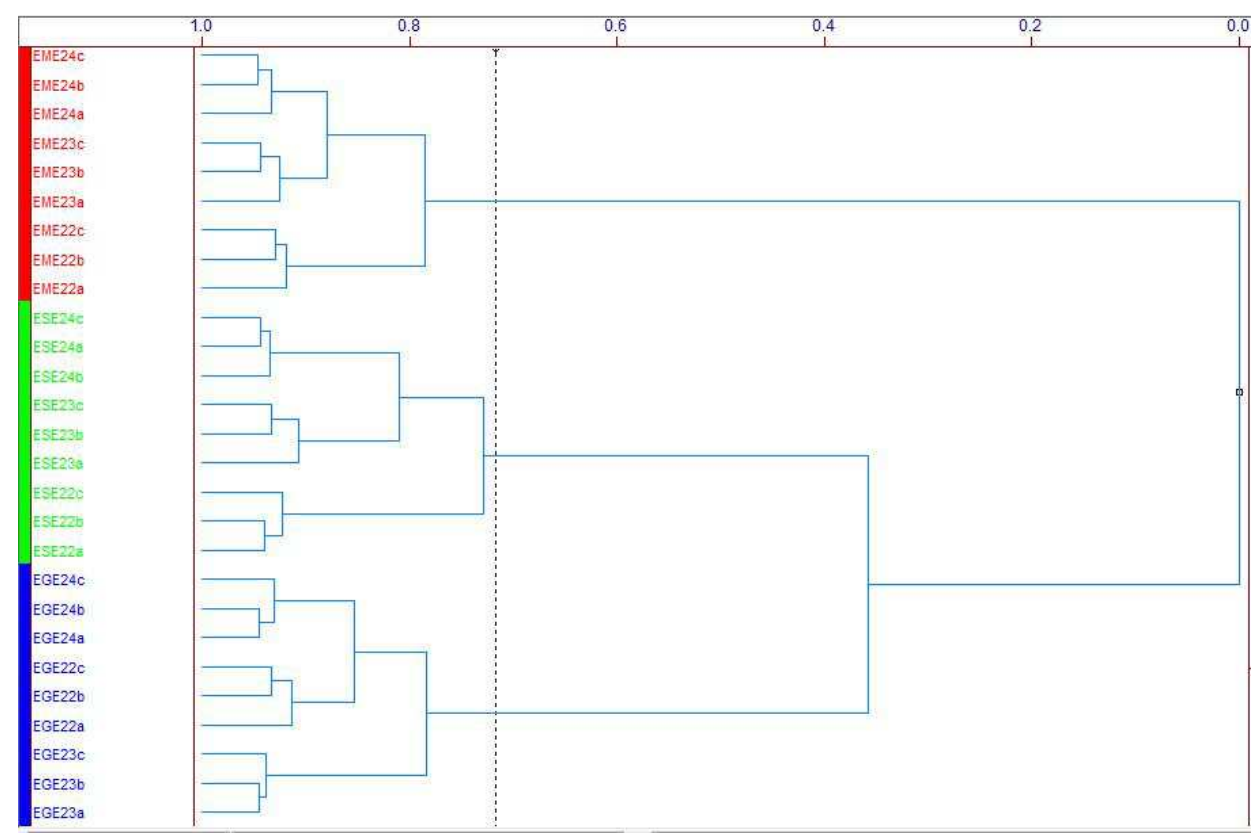

Na Figura 4 é possível observar a diferença entre as amostras de epóxidos devido à natureza do óleo vegetal utilizado na reação de epoxidação. A PC1 separa as amostras de epóxidos de girassol e soja das amostras de epóxidos de mamona. A PC2, por sua vez, discrimina as amostras de epóxidos de soja das amostras de epóxidos de girassol, formando três grupos distintos. As tendências observadas através da PCA foram confirmadas através do dendograma obtido pela HCA (Figura 5), no qual pode ser observada a presença de três agrupamentos. Este comportamento pode ser utilizado para reconhecer a origem do óleo utilizado na epoxidação. Avançando nesta pesquisa é possível definir uma metodologia de controle de qualidade de óleos epoxidados para espectroscopia associada à quimiometria. 


\section{CONCLUSÃO}

Os resultados obtidos mostram que é possível obter epóxidos a partir de ésteres de óleo de mamona, soja e girassol a partir da catálise quimioenzimática e que as taxas de conversão estão associadas ao tempo e quantidade de enzima utilizada. Em todos os casos o rendimento da reação aumenta conforme o aumento do tempo e da quantidade de enzima. Também pode ser observado que o óleo de mamona apresentou um rendimento inferior aos outros óleos.

O estudo indica, ainda, que é possível empregar a espectroscopia no infravermelho médio, associada à análise de componentes principais (PCA), no monitoramento da reação de epoxidação. Também indica a viabilidade de diferenciar epóxidos obtidos a partir de ésteres de óleos de girassol, mamona e soja através da espectroscopia no infravermelho médio associada à análise de componentes principais (PCA) e análise por agrupamento hierárquico (HCA).

\section{REFERÊNCIAS}

CAMPANELlA, A.; RUSTOY, E.; BALDESSARI, A.; BALTANÁS, M. A. Lubricants from chemically modified vegetable oils. Bioresource Technology, v. 101, p. 245-254, 2010.

NUNES, P. SIDEMAR. Produção e consumo de óleos vegetais no Brasil. Boletim eletrônico, deser, 2007. Disponível em:

<http://www.deser.org.br/documentos/boletim_completo/Boletim_159.pdf >. Acessado em: 19/02/14.

USDA. United States Department Of Agriculture. Foreign Agricultural Service, 2006. Disponível em: < http://www.fas.usda.gov/>. Acessado em: 18/07/13.

RÜSCH, M.; KLASS, gen.; WARNEL, S. Complete andpartialepoxidationofplantoilsby lipase-catalyzedperhydrolysis. Industrial Cropsand Products, v. 9, p. 125-132, 1999.

SCHNEIDER, R.C.S. et al. Chemo-Enzymatic Epoxidation of Sunflower Oil Methyl Esters. Journal Brazilian Chemical Society, v. 21, n.8 , p. 1473-1477, 2009.

KNOTHE, G. Analyzing biodiesel: standards and other methods. Journal of the American Oil Chemists' Society, v. 83, n.10, p. 823-833, 2006.

FERRÃO, M.F. et al. Simultaneous determination of quality parameters of biodiesel/diesel blends using HATR-FTIR spectra and PLS, $i$ PLS or siPLS regressions. Fuel, v. 90, n.2, p. 701-706, 2011. 
WERLANG, M. etal.Aplicação das Transformadas Wavelets em Dados de Espectroscopia no Infravermelho para a Determinação de Biodiesel e Óleo Vegetal em Blendas Biodiesel/Óleo Vegetal/Diesel. Orbital: The Electronic Journal of Chemistry, v. 5, n.4 , p. 242-248, 2013.

TRINDADE, M. M. et al. Espectroscopia no infravermelho por reflexão total atenuada horizontal (HATR) aplicada na identificação de óleos vegetais comerciais. Tecno-lóciga, v. 9, n.1 , p. 59-74, 2005.

SCHNEIDER, R.C.S. et al. Used frying oil biodiesel production: experimental factorial design and multivariate analysis. Tecno-lógica, v. 13, n.1 , p. 19-24, 2009.

MUELLER, D.et al. Fourier transform infrared spectroscopy (FTIR) and multivariate analysis for identification of different vegetable oils used in biodiesel production. Sensors, v. 13, p. 4258-4271, 2013.

SCHNEIDER, R.C.S. et al. Optimization of gas chromatographic-mass spectrometric analysis for fatty acids in hydrogenated castor oil obtained by catalytic transfer hydrogenation. Analytica Chimica Acta, v. 505, n.10, p. 223-226, 2004.

SILVERSTEIN, K. M.; BRASSLER, G. C.; MORRILL, T. C. Identificação geométrica de compostos orgânicos. Rio de Janeiro: Rio de Janeiro, 1994. 